\title{
COIL-UNCOILED CHAIN TRANSITION OF POLYETHYLENE OXIDE SOLUTIONS UNDER CONVERGENT FLOW
}

\author{
Andriy Pogrebnyak ${ }^{1,}{ }^{,}$Igor Chudyk ${ }^{2}$, \\ Volodymyr Pogrebnyak ${ }^{2}$, Iryna Perkun ${ }^{2}$
}

https://doi.org/10.23939/chcht13.04.465

\begin{abstract}
The coil-uncoiled chain transition under convergent flow of polyethylene oxide aqueous solutions has been studied. The possibility of this transition has been confirmed by the experiments. The fields of velocities and their gradients arising at the entrance of a small capillary during the convergent flow have been examined. It was found that water-polyethylene oxide system under convergent flow and certain flow regimes is self-regulating one with a negative feedback. The latter manifests itself in the following: accelerated longitudinal gradients of velocity lead to deformation of macromolecular coils, followed by a rearrangement of the flow in such a way as to increase the impact time of the longitudinal velocity gradient on macromolecules. The hydrodynamic field arising under the convergent flow provides a considerable degree of polymer uncoiling and coil-uncoil chain transition.
\end{abstract}

Keywords: macromolecule, polymer solution, convergent flow, hydrodynamic field, kinetic factor, refraction index, phase transition.

\section{Introduction}

Modern theory of polymer chain dynamics predicts the possibility of a coil-uncoiled chain phase transition in a longitudinal hydrodynamic field [1-3]. The hysteresis effects found in the theoretical analysis are the argument in favor of the fact that this transition must be of the first order. Experimentally obtained comparatively sharp dependences of the $\frac{\Delta n}{\Delta n_{\infty}}$ ratio value ( $\Delta n$ is a measured birefringence, $\Delta n_{\infty}$ is the maximum possible birefringence calculated for the concentration of the polymer solution) upon the longitudinal velocity gradient $\dot{\varepsilon}[4,5]$ could serve as an argument for the coil-uncoiled chain transformation when the molecules are in the

\footnotetext{
${ }^{1}$ University of Customs and Finance,

2/4 Volodymyr Vernadsky St., 49000 Dnipro, Ukraine

${ }^{2}$ Ivano-Frankivsk National Technical University of Oil and Gas,

15, Karpatska St., 76019 Ivano-Frankivsk, Ukraine

凶VTPogrebnyak@gmail.com

(C) Pogrebnyak A., Chudyk I., Pogrebnyak V., Perkun I., 2019
}

hydrodynamic field, generated between co-located slits or capillaries. But the change of $\frac{\Delta n}{\Delta n_{\infty}}$ with the growth of $\dot{\varepsilon}$ does not happen abruptly, as the concept of a first-order phase transition seems to require. The traditional explanation for the absence of an abrupt dependence of $\frac{\Delta n}{\Delta n_{\infty}}$ on $\dot{\varepsilon}$ is the polydispersity of the used material or the effects of the internal viscosity of the polymer chain.

However, Brestkin [3] shows that kinetic factors play the main role. The analysis was carried out within the framework of the nonlinear dumbbell model. The kinetic problem was solved using the Peterlin-de Gennes approximation. The obtained dependences of the uncoiling degree of the chain $\bar{\beta}$ on the rate of deformation $\dot{\varepsilon} \theta_{0} \quad\left(\theta_{0}\right.$ is the relaxation time of the macromolecule) at different times of the deformation effect $\frac{t}{\theta_{0}}$ for macromolecules with the number of segments $N=10^{3}$ indicate that with relatively prolonged impact of a flat hydrodynamic field on a set of isolated macromolecules, they pass into the uncoiled state if the dimensionless velocity of the deformation is equal to or exceeds the critical value of 0.5 . It must be mentioned that, if the value of $\frac{t}{\theta_{0}}$ is less than 10 , the transition of macromolecules to the uncoiled state in the hydrodynamic field is not possible, even if $\dot{\varepsilon} \theta_{0}$ is much higher than 0.5 .

A comparative analysis of the velocity fields in the gap of co-axially located capillaries and in the inflow area of the capillary indicates that the kinetic factors should acquire a major role in the flow of the polymer solution through a single capillary. Coil-uncoiled chain transition in case of a convergent flow (through a single capillary) is quite contradictory: most researchers believe that under such flows the time of impact of the hydrodynamic field on the macromolecular chain is comparable with the relaxation time of the macromolecule, and therefore it is not possible to obtain high values of the degrees of uncoiling [6]. 
The relevance of structural transitions studies under the convergent flow of polymer solutions is stipulated by practical application reasons. One of the main features of the polymer solution is the ability to equalize the front of oil displacement in a reservoir with a layered heterogeneity under specific conditions $[7,8]$. To clarify the mechanism and conditions for the demonstration of such properties polymer solutions, it is necessary to study the features of their flow in the model conditions of a porous medium, which (in the first approximation) are realized under convergent flow $[8,9]$. Another practically important task with the use of polymer solutions is a water-polymer hydraulic cutting [10]. In the jet head of the hydraulic cutting plant, a convergent flow occurs at which structural changes occur in the polymer solutions, and the latter results in a sharp increase in the cutting capacity of the polymer solution jet. Toms effect revealed as an experimental fact in the late forties, up to now has been causing great difficulties when interpreting it from the standpoint of turbulent flow hydrodynamics modern ideas. Among the attempts to explain the nature of Toms effect, lying in drag reduction by the polymeric components, special place is taken by a hypothesis, based on a strong deformation effect of a nearthe-wall turbulence on macromolecules [11].

The outlined information indicates that the relevance of the studies carried out in [4-6] remains today, and a lack of understanding of the processes that occur under convergent flow of polymer solutions generates a lot of misunderstandings and errors in the interpretation of experimental results.

So the aim of this work is to determine peculiarities of macromolecules deformation behaviour under the convergent flow of polymer solution that would allow to solve the issues related to the practical application of polymer solutions.

\section{Experimental}

The polarization optical unit is mounted on a horizontally located optical bench and consists of a light source, a lens system for creating a parallel beam of light, a polarizing microscope, a light filter and a quarter wavelength plate. The source of light is a mercury quartz lamp DRSh-250.

In the measurement of $\Delta n$, the Becker compensator was used. The birefringence of the polymer solution subjected to the uniaxial deformation, due to the optical anisotropy and orientation of macromolecules segments, was calculated according to Eq. (1) [1]:

$$
\Delta n=\frac{2 \pi}{9} \frac{\left(n_{c}^{2}+2\right)^{2}}{n}\left(\alpha_{1}-\alpha_{2}\right) N^{*} F_{0}
$$

where $n_{c}$ is the index of the solution refrection; $\left(\alpha_{1}-\alpha_{2}\right)$ is the difference in the polarizabilities of the segments; $N^{*}$ is their quantity per unit volume; $F_{0}=\frac{\left(3 \cos ^{2} \gamma-1\right)}{2}$ is the orientation parameter; $\cos ^{2} \gamma$ is the mean square cosine of the orientation angle $\gamma$ of the segments, measured relative to the principal direction of extension of the solution. The value $\left(\alpha_{1}-\alpha_{2}\right)$ is defined as:

$$
\left(\alpha_{1}-\alpha_{2}\right)=\left(\alpha_{1}-\alpha_{2}\right)_{\ell}+\left(\alpha_{1}-\alpha_{2}\right)_{f}+\left(\alpha_{1}-\alpha_{2}\right)_{f s}
$$

where $\left(\alpha_{1}-\alpha_{2}\right)_{\ell}$ is the difference in the polarizabilities of the segment, caused by its own optical anisotropy; $\left(\alpha_{1}-\alpha_{2}\right)_{f}$ and $\left(\alpha_{1}-\alpha_{2}\right)_{f s}$ are contributions to the difference between the polarizabilities of the segment, due to the anisotropy of the macroform of the molecular chain and the anisotropy of the segment itself (anisotropy of the microform).

According to [12] $\left(\alpha_{1}-\alpha_{2}\right)_{f} \rightarrow 0$ for the maximum uncoiled state of the macromolecule, and

$$
\left(\alpha_{1}-\alpha_{2}\right)_{f s}=\left(\frac{n_{p}^{2}-n_{s}^{2}}{4 \pi \cdot n_{s}}\right)\left(L_{2}-L_{1}\right) \frac{M_{s}}{\rho_{p} N_{A}}
$$

where $n_{p}$ and $n_{s}$ are indices of refraction of the polymer and the solvent, respectively; $L_{1}$ and $L_{2}$ are the coefficients, depending on the segment shape asymmetry; $N_{A}$ is the Avogadro's number; $M_{s}$ is the molecular mass of the segment; $\rho_{p}$ is the polymer density, $\mathrm{g} / \mathrm{cm}^{3}$.

To calculate $\Delta n_{\infty}$ for PEO solutions we took $\left(\alpha_{1}-\alpha_{2}\right)=18 \cdot 10^{-25} \mathrm{~cm}^{3} ; M_{s}=308 ; \rho_{p}=1.12 \mathrm{~g} / \mathrm{cm}^{3} ;$ $n_{s}=1.338 ; n_{p}=1.46$. The value $L_{2}-L_{1}$ was equal to 5.4. It was found out that the contribution of the PEO segment anisotropy to the value $\Delta n_{\infty}$ is about $36 \%$ [13].

\section{Results and Discussion}

Theoretical analysis of the kinetic factors influence on the degree of uncoiling of the macromolecular chain, and consequently on $\frac{\Delta n}{\Delta n_{\infty}} v s . \dot{\varepsilon}$ dependence in case of a convergent hydrodynamic field, realized when the polymer solution flow through a single capillary encounters considerable difficulties. First of all, they are due to the fact that, in contrast to coaxially located capillaries, in this case a much greater influence of uncoiling macromolecules on the structure of the hydrodynamic field perturbing them is observed [14], as well as the appearance of an unstable flow regime at supercritical velocities (Fig. 1). Therefore, when investigating the influence of kinetic factors on the degree of uncoiling of the chain in the convergent flow (in the inflow area of the capillary), first of all, experimental proof of the possibility of a coil-uncoiled chain transition was used.

In accordance with the obtained pictures of the current lines in the inflow area of the capillary [15], we 
assume that the effect of the hydrodynamic field on the element of the solution volume, leading to the stretching of this element, starts at some distance $y_{s}$ from the center of the capillary inlet $y=0$. The axis $y$ in this case is the axis of symmetry of the flow and is connected with the center of the capillary inlet. We believe that if $y>y_{s}$, the macromolecules in the inflow area of the capillary are not subjected to significant deformation effects.
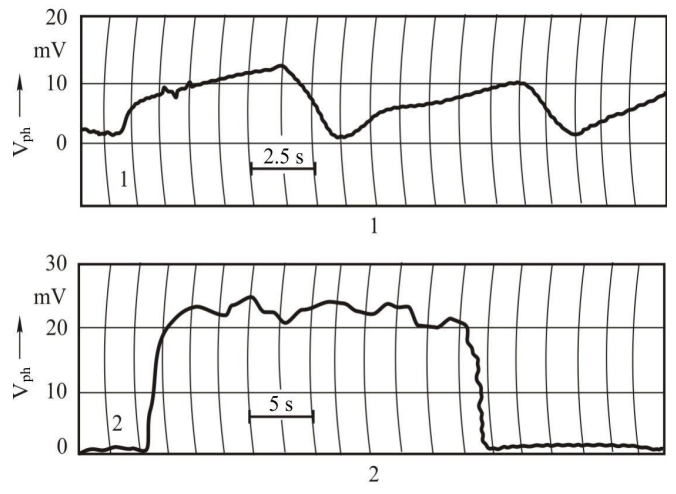

Fig. 1. Time variation in the intensity of the laser beam in the inflow area of the capillary: $d_{c}=0.5 \cdot 10^{-3} \mathrm{~m} ; l_{c}=0.21 \cdot 10^{-3} \mathrm{~m} ; M_{P E O}=4 \cdot 10^{6} ; C_{P E O}=0.03 \%$; $\bar{u}$ is $1 \mathrm{~m} / \mathrm{s}(1)$ and $2.5 \mathrm{~m} / \mathrm{s}(2)$

When the highly dilute PEO solutions flow through the capillary, the velocity field is practically not deformed, and the measured effective viscosity does not differ from the viscosity of the solvent. Therefore, we can assume that a Newtonian fluid flows through the capillary. In the first approximation, the velocity field is radial: $u=\frac{q}{2 \pi \cdot y^{2}}$ ( $q$ is the flow rate of the liquid through the capillary). The corresponding longitudinal velocity gradient is equal to $\dot{\varepsilon}=\frac{q}{\pi \cdot y^{3}}$.

The macromolecular chain undergoes a deformation effect during the time it moves from $y=y_{s}$ to $y=d_{c} / 2\left(d_{c}\right.$ is the capillary diameter):

$$
t=\int_{\frac{d_{c}}{2}}^{y_{s}} \frac{d y}{u(y)}=\frac{2}{3} \cdot \frac{\pi \cdot y_{s}^{3}}{q}=\frac{2}{3 \cdot \dot{\varepsilon}_{c r}}
$$

where $y_{s}$ is a distance from the center of the inlet of the capillary, from which an appreciable deformation of the chain begins. At $y=y_{s}$ the velocity gradient is equal to $\dot{\varepsilon}_{c r}$. If we use the Deborah criterion $\left(\theta_{c}=\frac{0.5}{\dot{\varepsilon}_{c r}}\right)$ for a very dilute polymer solution $\left(C[\eta]_{0}<<1\right)$, when the solution relaxation time at a given concentration $\theta_{c}$ is practically equal to the relaxation time when extrapolated to infinite dilution $\theta_{0}$, then $t=4 / 3 \theta_{0}$.

Thus, when a very dilute polymer solution flows through the capillary, the time of impact of the longitudinal velocity gradient is comparable with the relaxation time of the macromolecule. It follows from the data represented in [3] that at such time the hydrodynamic field affects the macromolecular chain, and it is not possible to obtain high values of the uncoiling degree. Therefore, skeptical attitude regarding the strong deformation effect of a convergent hydrodynamic field on macromolecular coils in dilute solutions is justified.

Using the velocity distribution on the flow axis, we obtained the distribution of their gradients, which is shown in Figs. 2a and 3.

The maximum gradient is realized not at the inlet to the capillary, but at a certain distance (Fig. 2a, curve 2). The value $\dot{\varepsilon}_{\max }$ in the inflow area of the capillary during the flow of the polymer solution is substantially lower than in the flow without polymer additives, i.e. the effect of the hydrodynamic field leads to the changes in the polymer system that cause the velocity field to be rearranged so as to reduce the longitudinal velocity gradients. From Fig. 3 it is clear that the maximum values of the velocity gradient in the inflow area of the capillary (curves 2 and 3 ) depend weakly on $\bar{u}$. A further increase in the pressure drop leads to an increase in the outflow velocity, and the maximum velocity gradient realized on the flow axis remains practically constant Fig. 3, curves 2 and 3). The region of its realization shifts farther from the inlet to the capillary, and the width of the plateau, which is observed on the dependence of $\dot{\varepsilon}$ on $y$ (Fig. 2a, curve 2), increases, i.e. the zone in which the liquid acceleration occurs is increased.
Fig. 2. The distribution of the velocity gradient (a) and deformation factor (b) on the flow axis under convergent flow: $d_{c}=0.5 \cdot 10^{-3} \mathrm{~m} ; l_{c}=0.21 \cdot 10^{-3} \mathrm{~m} ;$ $M_{P E O}=4 \cdot 10^{6} ; \bar{u}=1.15 \mathrm{~m} / \mathrm{s}$. For (a): water (1) and $C_{P E O}=0.03 \%$ (2). For (b): $C_{P E O}=0.03 \%$

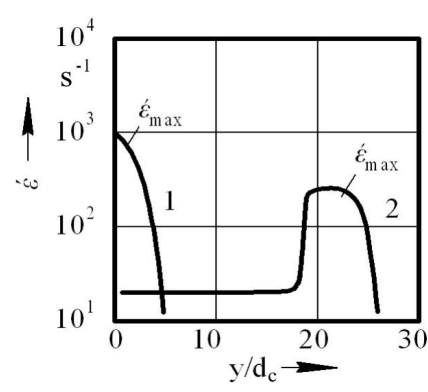

a)

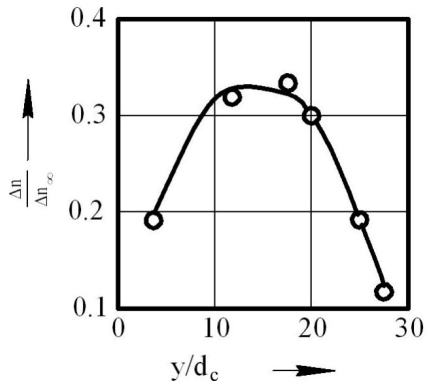

b) 
Images of inflow patterns of polymer solution into the capillary obtained in crossed polaroids indicate the localization of the birefringent zone near the axis of the flow. The polarization planes of the polaroids were oriented at an angle of $45^{\circ}$ to the flow axis. The birefringence passes through a maximum at sufficiently large $\bar{u}$ (Fig. 2b). The position of the maximum on the curve $\frac{\Delta n}{\Delta n_{\infty}}=f\left(\frac{y}{d_{c}}\right)$ corresponds to the zone with the maximum longitudinal velocity gradient (Fig. 2a, curve 2) in the inflow area of the capillary. For these flow regimes there is an unstable flow pattern, which can be clearly seen from the diagrams of the time variation of the intensity of the laser beam (Fig. 1), passing at a distance of one diameter from the inlet to the capillary. Recording of pulsations in the intensity of the laser beam was performed in the presence of birefringence in the inflow area of the capillary. When measuring the birefringence of solutions, only the maximum values from the sets $\Delta n$ corresponding to a given average velocity were taken into account.

The results, presented in Fig. 4, prove the possibility of macromolecules transition into a highly uncoiled state under convergent flow conditions. The ratio of the measured birefringence to the maximum possible value reaches 0.37 (Fig. 4, curve 1), which corresponds to $61 \%$ of the uncoiling degree of the macromolecule. The degree of uncoiling in percentage is defined as $\sqrt{\frac{\Delta n}{\Delta n_{\infty}}} \cdot 100 \%$. The increase in concentration, when $C[\eta]_{0} \geq 0.8$ leads to a significant decrease in the deformation factor (Fig. 4, curve 4). Experiments performed with an aqueous solution of PEO with the molecular mass of $4 \cdot 10^{6}$ and a concentration of $0.1 \%$ $\left(C[\eta]_{0}=1.72\right)$ gave a maximum value of $\frac{\Delta n}{\Delta n_{\infty}}$ ratio close to 0.09 . This means that in the case of moderately concentrated solutions, the deformation effect of the convergent flow is $30 \%$.

The experiment also demonstrated: when very dilute PEO solutions flow through the capillary at $C[\eta]_{0} \leq 0.2$, the velocity field is practically not deformed, and the $\frac{\Delta n}{\Delta n_{\infty}}$ ratio is much lower than 0.1. At the same time, it is complicated to obtain accurate values of $\frac{\Delta n}{\Delta n_{\infty}}$ due to a sharp decrease in the sensitivity threshold of birefringence.

The data in Fig. 4 allow us to explain the behavior of macromolecules with different molecular masses at different flow rates. It can be seen that the dependence of
$\left(\frac{\Delta n}{\Delta n_{\infty}}\right)_{\max }$ on $\bar{u}$ can be divided into three regions.

Regions I and III are characterized by a monotonous increase in the dimensions of the PEO molecular coils with an increase in the average flow velocity, and the transition region (region II) is spasmodic. Comparative analysis of Fig. 4 and Fig. 3 shows that in the region I the increase of $\bar{u}$ is accompanied by an increase of $\dot{\varepsilon}$, which causes an increase in the dimensions of molecular coils. The velocity gradients that are realized in the inflow region of the capillary are somewhat lower than those of water flowing at the same flow rate. When a certain critical velocity gradient is reached, a sharp transformation of the dimensions of the molecular coils occurs. The latter leads to a substantial rearrangement of the velocity field in such a way as to lower the longitudinal gradient of the velocity, but not lower than its critical value. A further increase of $\bar{u}$ has a little effect on the deformation factor and on $\dot{\varepsilon}_{\max }$ in the region III. The fact that a significant change in velocity does not lead to a strong change in the longitudinal velocity gradient indicates a nonlinear (at least cubic nonlinearity) effect of the degree of uncoiling of the macromolecules on the realized velocity gradients. In other words, in region I, a considerable deformation of molecular coils (approximately $30 \%$ ) causes significantly smaller changes in the velocity field than in region III, where a change in the degree of uncoiling from 50 to $61 \%$ lowers the velocity gradient in comparison with water by 2 orders of magnitude (Fig. 3).

From the data presented in Fig. 4, (curves 1-3) and control experiments, it follows that for the concentrations within the interval of $0.2 \leq C[\eta]_{0} \leq 0.8$, and the decrease in the molecular weight of PEO from $6 \cdot 10^{6}$ to $3 \cdot 10^{6}$ leads to the increase in the deformation factor from 0.29 to 0.37 , in contrast to the case when the molecules are in a hydrodynamic field, generated between coaxially located slits or capillaries. It was found in [12] that practically complete uncoiling of PEO molecules is possible in the gap between co-located gaps, the deformation factor has reached more than 0.8 . At the same time, a decrease in the molecular weight of PEO from $6 \cdot 10^{6}$ to $3 \cdot 10^{6}$ led to a decrease in the deformation factor from 0.8 to 0.6 .

An increase in the macromolecules concentration in the solution in the case of flow through a single capillary leads to their active influence on the structure of the hydrodynamic field. The observed change in the velocity field contributes to the increase of $\frac{t}{\theta_{0}}$, and, consequently, the deformation factor. $U p$ to the concentrations of $C[\eta]_{0} \leq 0.2$, these changes in both the 
flow structure and the size of molecular coils with growth of $\bar{u}$ occur fairly smoothly, and only at concentrations of the aqueous solution of PEO of $0.2 \leq C[\eta]_{0} \leq 0.8$ they occur abruptly. For these solutions, the value of $\frac{t}{\theta_{0}}$ is more than 10 (Fig. 2), and this stipulates a high degree of uncoiling of the macromolecular coil. An abrupt change of $\frac{\Delta n}{\Delta n_{\infty}}$ with an increasing flow velocity indicates that the action of the hydrodynamic field leads to conformational instability of macromolecular coils, and the coil-unfolded transition is a first-order phase transition.

The index of refraction $(n)$ of PEO differs from index $\left(n_{0}\right)$ of the solvent-water. When $n \neq n_{0}$ we should take into account the shape effect, and we did that while obtaining the data in Figs. $2 b$ and 4. Therefore, there may be concerns that high values of the deformation factor are obtained due to complications related to the consideration



Fig. 3. Dependence of the maximum velocity gradient in the inflow area of the capillary from the average flow velocity: $d_{c}=0.5 \cdot 10^{-3} \mathrm{~m} ; l_{c}=0.21 \cdot 10^{-3} \mathrm{~m}$. For (1): water. For (2): $M_{P E O}=4 \cdot 10^{6}$ and $C_{P E O}=0.02 \%$. For (3): $M_{P E O}=4 \cdot 10^{6}$ and $C_{P E O}=0.03 \%$

Fig. 5. Images of current lines in the capillary inflow area and the dependence of the effective viscosity of the polystyrene solution in the bromoform on the average flow velocity: $d_{c}=0.3 \cdot 10^{-3} \mathrm{~m} ; l_{c}=1.0 \cdot 10^{-3} \mathrm{~m} ; M_{P S}=2.3 \cdot 10^{6}$ and $C_{P S}=0.05 \mathrm{~kg} / \mathrm{m}^{3}$ of the shape effect. This is especially true for PEO, in which the anisotropy of the segment is very small. The selection of a solvent with the same index of refraction as the polymer allows to get rid of these complications, but for PEO, because of the low anisotropy of the segment, it becomes practically impossible to measure the birefringence of such a solution.

To confirm the conclusion about the strong deformation effect of a converging hydrodynamic flow on macromolecular coils, experiments were conducted with a solution of polystyrene in bromoform, where $n=n_{0}$. For polystyrene solutions in bromoform, practically all the basic regularities, characteristic for PEO solutions are observed when they flow through short capillaries (Fig. 5). The deformation factor when the polystyrene solution in the bromoform flows through the capillary in the mode, described in Figs. 2, 3, 5 and reached 0.23 and 0.4, which correspond to $48 \%$ and $63 \%$ of the uncoiling degree of the molecular coils of the polystyrene.

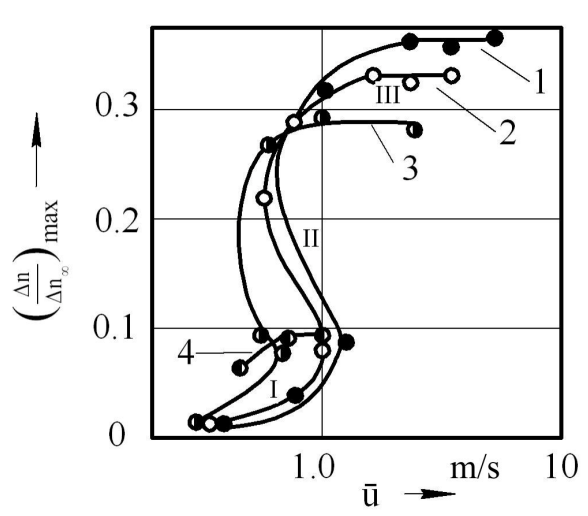

Fig. 4. Dependence of the deformation factor maximum values in the capillary inflow area on the average outflow rate: $d_{c}=0.5 \cdot 10^{-3} \mathrm{~m} ; l_{c}=0.21 \cdot 10^{-3} \mathrm{~m}$. For $(1): M_{P E O}=3 \cdot 10^{6}$ and $C_{P E O}=0.03 \%$. For (2): $M_{P E O}=4 \cdot 10^{6}$ and $C_{P E O}=0.03 \%$.

For (3): $M_{P E O}=6 \cdot 10^{6}$ and $C_{P E O}=0.03 \%$. For (4): $M_{P E O}=4 \cdot 10^{6}$ and $C_{P E O}=0.1 \%$

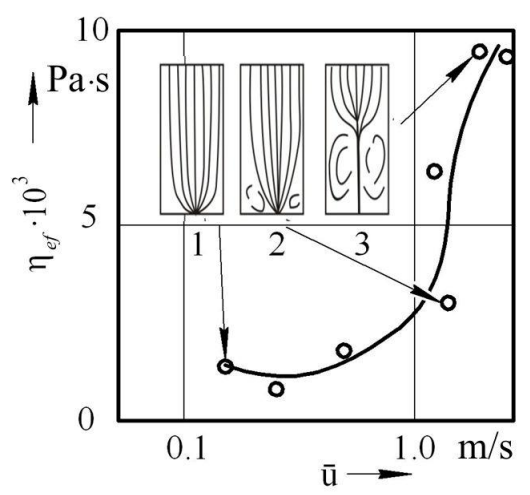


The examined data prove that the water-flexible polymer system under conditions of convergent flow under certain flow regimes is self-regulating with a negative feedback. The latter manifests itself in the following: increasing longitudinal velocity gradients lead to deformation of macromolecular coils, and this in turn causes a rearrangement of the flow structure in such a way as to increase $\frac{t}{\theta_{0}}$ and reduce the longitudinal velocity gradients. The latter cannot be lower than certain critical values sufficient for uncoiling macromolecules. If they are still lower than $\dot{\varepsilon}_{c r}$, the macromolecules will collapse and cease to affect the velocity field, while the velocity gradient will increase dramatically, and this will lead to a substantial deformation of the macromolecular coils, and everything will be repeated anew. That is, the system itself chooses such a minimum velocity gradient and the time of action of the hydrodynamic field that would be sufficient to uncoil the macromolecular coils. The increase in flow velocity as a result of nonlinear effects leads to an insignificant further increase in the deformation factor, but this is sufficient to stabilize the characteristic velocity gradient for a given system.

\section{Conclusions}

The data being presented prove that the degree of extension of polyethylene oxide molecular coils under the convergent flow depends significantly upon the impact of kinetic factors. Water-polyethylene oxide system for the concentrations within the interval of $0.2 \leq C[\eta]_{0} \leq 0.8$ under the conditions of the convergent flow and certain flow regimes is self-regulating with a negative feedback. The increasing longitudinal velocity gradients lead to deformation of macromolecular coils, and this in turn causes a rearrangement of the flow structure in such a way as to increase $\frac{t}{\theta_{0}}$. The possibility of a coil-uncoiled chain transition under convergent flow of semi-diluted polyethylene oxide solutions with the achievement of the degree of macromolecular chain uncoiling by more than $61 \%$ was experimentally proved.

\section{References}

[1] Brestkin Yu., Gotlib Yu., Klushin L.: Vysokomol. Soyed., 1989, A31, 1704. https://doi.org/10.1016/0032-3950(89)90023-3
[2] Darinskii A., Lyulin A., Saphiannikova M.: Int. J. Polym. Mater. Polym. Biomater., 1993, 22, 15.

https://doi.org/10.1080/00914039308012053

[3] Brestkin Yu.: Acta Polymer., 1987, 38, 470.

https://doi.org/10.1002/actp.1987.010380803

[4] Keller A., Odell J.: Colloid. Polymer. Sci., 1985, 263, 181. https://doi.org/10.1007/BF01415506

[5] Odell J., Keller A., Miles M.: Polymer, 1985, 26, 1219.

https://doi.org/10.1016/0032-3861(85)90256-3

[6] Brestkin Yu., Saddikov I., Agronova S. et al.: Polym. Bull., 1986, 15, 147. https://doi.org/10.1007/BF00263393

[7] Pogrebnyak V., Perkun I., Pogrebnyak A.: Am. J. Sci. Eng. Techn., 2016, 1, 53. https://doi.org/10.11648/j.ajset.20160102.16 [8] Pogrebnyak V., Voloshin V., Naumchuk M.: J. Eng. Phys. Thermophys., 2005, 78, 963. https://doi.org/10.1007/s10891-006-0019-z

[9] Pogrebnyak A., Perkun I. V., Pogrebnyak V. G.: J. Eng. Phys. and Thermophys, 2017, 90, 1219. https://doi.org/10.1007/s10891017-1677-8

[10] Pogrebnyak A.: Nauk. Visnyk LNLTU Ukrainy, 2017, 27, 173. https://doi.org/10.15421/40270342

[11] Kryvenko G., Pogrebnyak A., Perkun I., Pogrebnyak V.: Petrol. Sci. Eng., 2017, 1(2), 30.

https://doi.org/10.11648/j.pse.20170102.12

[12] Tsvetkov V.: Zhestko-Tsepnye Polymernye Moleculy. Nauka, Leningrad 1986.

[13] Brestkin Yu., Agranova S., Dyakonova N.: Vysokomol. Soyed. B, 1989, 31, 844 .

[14] Borisov O., Zhulina E., Polosckiy A., Darinskiy A.: Osnovy Phyziki Macromolekul. Univ. ITMO, Sankt-Peterburg 2015.

[15] Ivanyuta Yu., Pogrebnyak V., Naumchuk N., Frenkel S.: J.

Eng. Phys., 1985, 49, 1192. https://doi.org/10.1007/BF00871917

Received: October 19, 2018 / Revised: December 17, 2018 / Accepted: April 15, 2019

\section{ПЕРЕХІД КЛУБОК-РОЗГОРНУТИЙ ЛАНЦЮГ ПРИ ЗБІЖНІЙ ТЕЧІЇ РОЗЧИНІВ ПОЛІЕТИЛЕНОКСИДУ}

Анотація. Досліджено перехід клубок-розгорнутий ланцюг при збіжній течії водних розчинів поліетиленоксиду. Експериментально підтверджено можливість такого переходу. Вивчено поля швидкостей $i$ їх градієнтів, щзо виникають на вході короткого капіляра при збіжній течії. Встановлено, щзо система вода-поліетиленоксид при збіжній течії за певних режимів є саморегулюючою з негативним зворотним зв'язком. Показано, що зростаючі поздовжні градієнти швидкості призводять до деформаиії макромолекулярних клубків, щчо, в свою чергу, викликає перебудову структури потоку таким чином, щьоб збільшити час впливу поздовжнього градієнта швидкості на макромолекули. Гідродинамічне поле, яке виникає в умовах збіжної течії, приводить до значного ступеня розгорнення молекул полімеру і до переходу клубок-розгорнутий ланцююг.

Ключові слова: макромолекула, розчин полімеру, клубок-розгорнутий ланцюг, збіжна течія, гідродинамічне поле, кінетичний фактор, показник заломлення, фазовий перехід. 